\title{
The Role of Digital Technologies During Relationship Breakdowns
}

\author{
Wendy Moncur \\ Living Digital Group, \\ University of Dundee \\ Dundee, UK \\ wmoncur@dundee.ac.uk
}

\author{
Lorna Gibson \\ University of Dundee, \\ Dundee, UK \\ lgibson@computing.dundee.ac.uk
}

\author{
Daniel Herron \\ Living Digital Group, \\ University of Dundee \\ Dundee, UK \\ d.herron@dundee.ac.uk
}

\begin{abstract}
Relationship breakdowns are undoubtedly difficult. Access to and use of technology can exacerbate the situation. In our networked society, shared lives generate vast amounts of shared digital data which can be difficult to untangle, whilst social media can provide an outlet to emotions that can take a public and often persistent form. In this paper, we report on a qualitative study that considered the role of technology in the process of a relationship breaking down. Four main themes emerged in our findings: communicating about the separation, change in social status, shared digital assets, and moving on. Opportunities for design are identified in reducing misunderstandings via $\mathrm{CMCs}$, enhancing social media, supporting intimacy in distributed families, and refining service provision.
\end{abstract}

\section{Author Keywords}

Divorce; Separation; HCI; life transitions; computermediated communications; service design.

\section{ACM Classification Keywords}

H.1.1 [Models and Principles]: User/Machine Systems human factors. H4.3 [Information systems applications]: Communications applications; K.4.2 [Computing Milieux]: Computers and Society

\section{INTRODUCTION}

The breakdown of a relationship is undoubtedly a stressful life event. It is also, on the whole, an unplanned one. While many people plan for inevitable events such as death by considering wills and funeral preferences, and others plan for hoped-for events such as weddings and civil ceremonies, advance planning for a relationship breakdown verges on being taboo. This is despite the fact that $42 \%$ of marriages in the UK end in divorce [29], with a slightly

Permission to make digital or hard copies of part or all of this work for personal or classroom use is granted without fee provided that copies are not made or distributed for profit or commercial advantage and that copies bear this notice and the full citation on the first page. Copyrights for thirdparty components of this work must be honored. For all other uses, contact the Owner/Author.

Copyright is held by the owner/author(s).

$C S C W$ '16, February 27-02 March, 2016, San Francisco, CA, USA ACM 978-1-4503-3592-8/16/02.

DOI: http://dx.doi.org/10.1145/2818048.2819925 lower rate predicted breakdown for civil partnerships [30]. There are no statistics monitoring the breakdown of nonformalized relationships in the UK.

It is not surprising that people do not usually plan for relationship breakdowns. For example, the traditional idealized Western model for heterosexual marriage is to expect the relationship to be permanent and monogamous, affirmed through public vows of lifelong commitment. To visibly plan for the ending of a relationship goes against the optimism that characteristically accompanies commitment to that relationship, and one can see how this serves as a reason for avoiding any explicit planning of this kind. A notable exception to this lack of planning lies in the growing trend to have formal marriage contracts, with prenuptial agreements that specify quite tightly against relationship breakdown. In the absence of advanced plans, relationship breakdown can be complicated where there is shared ownership of artifacts (both digital and physical). Dividing these artifacts can be wrought with tensions around ownership, and imbued with emotion.

Relationship breakdown of co-habiting individuals is relevant to the $\mathrm{CSCW}$ community. When a couple separate, the disentangling of their shared life now incorporates digital aspects, including changes in requirements for device and account ownership and use, representations of self through online channels, and access to digital materials such as photos and music. Moving on may also involve digital technologies - for example, with communication around parenting responsibilities conducted through computer-mediated communications (CMCs).

In this paper, we report on qualitative research undertaken to understand the intersection between technology and relationship breakdowns. We first situate the research in the context of previous work that considers technology use during relationship breakdown and other significant points in the human lifespan. We then describe the methodology and context of the research that we carried out, and the findings. These findings are used as input to a discussion on opportunities for design that take relationship breakdown into account.

\section{RELATED WORK}

There is now a growing body of work looking at the design of technology that takes significant points across the digital 
lifespan into account. Work so far on expected and unexpected transitions that occur across the human lifespan has included moving home [33], motherhood [13], distributed families (through work separation or divorce) $[28,37,38]$, weddings [20] and the death of a loved one $[18,23]$. An emerging theme in this body of work is the complex interweaving of social, psychological and technical factors that influence users' experience of technology at these significant points in their lives. Online identity is - understandably - profoundly influenced by offline life events. Just as the end of life has significant consequences for one's Facebook profile [3,22], so too does separation.

\section{Relationship breakdown}

A number of studies conducted in the social sciences have identified the stages of relationship breakdown, and the impact that it has on an individual's wellbeing $[1,12,16,31,34]$. Within this paper, we refer to relationship breakdown specifically in the context of the end of a cohabiting relationship, as this was the experience of our participants. Relationship breakdown does not happen as a series of discrete events, but as a process that begins with feelings of estrangement during the relationship. For married couples, this process includes a landmark civic event, divorce [1]. The process continues until after the partners are (usually) no longer cohabiting - and if married, until after they are legally divorced. Markers of the end of the process include the ability to create an identity independently of the former relationship. The process brings with it stressors that former partners have to come to terms with (e.g. loss of emotional support), moderators that can positively or negatively impact on those stressors (e.g. individual, interpersonal or structural resources), and adjustments that they need to make (e.g. identity no longer being tied to former relationship). It can increase psychological distress and decrease life satisfaction: over $43 \%$ of individuals involved in a relationship breakdown reported a decline in wellbeing (where wellbeing was a combined measure of psychological distress and life satisfaction) [31]. However, opportunities for personal growth and reflection can emerge out of relationship breakdown. Tashiro and Frazier found that individuals undergoing a breakup could identify an average of five positive changes that they could make to improve their romantic lives, and future relationships, following a breakup [34].

Research carried out by Hall and Fincham explored the impact that attributions and forgiveness have on reconciliation and relationship breakdown, following an act of infidelity [16]. They found that in order to promote forgiveness and reconciliation between couples, the attributions relating to the infidelity should be addressed in therapy sessions. The work draws an interesting conclusion, that reconciliation between partners is not the optimal outcome for the individuals - it is forgiveness that couples should strive to achieve, as it brings with it significant emotional and physical health benefits.

\section{Computer-mediated communications and relationship}

Increasingly, digital technologies play a role in supporting communication both during relationships and during relationship breakdown, and subsequently in moving on. They even take the blame for a third of marital breakdowns [40]. Digital technologies can be used to promote intimacy during relationships, as well as to support communication after separation. For example, Jiang and Hancock found that during a long distance relationship, couples reported equal or better levels of relationship stability, satisfaction and trust than their geographically close counterparts [6]. This was accomplished by utilizing a range of interpersonal media to communicate. Frequently used CMCs provided long distance couples with more opportunities for open selfdisclosure, increasing the levels of intimacy between partners. After a breakup, some ex-partners reported positive uses of digital technologies - e.g. using email to share photographs of their children with one another [28], and facilitating productive interactions that focused their asynchronous communications on a common connection their child(ren). However, other studies have found that communication between divorced parents in distributed family structures is very limited, and that digital technologies may hinder not help [38].

\section{Digital artifacts}

Alongside the role of digital technologies in supporting communication, they played an important role in documenting the relationship, through materials including photos, emails, text messages, status updates and posts on social network sites (SNS). Sas and Whitaker [32] considered the fate of these digital artifacts when a relationship broke down, finding that artifacts previously cherished for their positive effects during a relationship (such as facilitating intimacy and triggering reminiscence) caused negative issues for the ex-partners by fulfilling those same roles after the relationship ended, in a now unwelcome manner. They proposed that disposing of these digital artifacts could be a solution to these issues, with design implications raised around the ways in which the disposal could be carried out; arguing that disposing of artifacts from the relationship in the right way could be therapeutic for individuals as they move towards forming a new self-concept separate from being part of a couple.

These issues with disposal of digital artifacts are highlighted again in research exploring the role of social media in personal digital archives. The facilities on Facebook in particular are regarded as limited with respect to curating digital media. While artifacts can be hidden from other users or deleted entirely, there are no facilities for hiding artifacts from their creator, or archiving them [39]. In situations such as relationship breakdown, the option to selectively dispose of or discretely manage digital 
artifacts, rather than simply keeping or deleting it, could help individuals to move on.

The concept of reconstructing one's identity through disposal (or curation) of digital artifacts [29] is echoed in a more literal way in research investigating the stresses of gender transition (another profound life transition) on Facebook. During gender transition, individuals have been found to actively manage their online identity as they discover and reinvent their sense of self, and in doing so these individuals experience substantial levels of stress while updating and informing connections on social media about their experiences [15]. Haimson et al. found that although Facebook provides the means to address different groups independently from one another, allowing individuals to tailor news of their transition to specific social groups, the task itself is complex and stressful.

\section{Sharing news}

Beyond the literature on relationship breakdown and managing online identity, recent work on use of technology during other disruptive life transitions is relevant. For example, when parents have a baby in Neonatal Intensive Care, they are very selective in who they share updates with when they have bad news about the baby, preferring not to use social media to broadcast to their entire online social network [24]. When there is a suggestion that parents are in some way 'to blame' for a sick baby's illness - for example, through passing on an inherited condition - they tell no-one, online or off. It is reasonable to expect parallels in the context of relationship breakdown, and for individuals to be reluctant to apportion blame to themselves via social media. In contrast, online social media may be used actively in a range of practices related to dying, the funeral, grief and memorialization $[25,36]$ - for example, to share the news efficiently with all social network members about the event (death) and subsequent funeral arrangements [23], and to express individual feelings of loss [4]. Again there are likely parallels with relationship breakdown.

\section{METHODOLOGY}

The goal of this work was to consider where technology featured during the process of relationship breakdown, and how it was used to facilitate or hinder that process. We focus on the ecology of technology use across the transition period of separating (specifically moving from a cohabiting partnership back to individual living).

\section{Participants}

The work was based within a small geographical area of the UK. Due to the sensitivity of the subject, participants were recruited through convenience sampling and snowballing. The diversity of the group recruited can be seen in Table 1 . Participants ranged in age from 27 to 68 , had been in a relationship between 4 and 34 years, and had been separated between 4 months and 7 years. Gender was mixed
(3 male, 5 female). It should be noted that two participants ( $F$ and $G$ ) were an amicable divorced couple, and the exhusband recruited the ex-wife into the study. They were interviewed separately. We made no restrictions on the type of relationship that participants had experienced (for example, marriage, civil partnership, co-habiting, heterosexual or homosexual), and indeed did not ask participants about this. Nor did we ask specifically about the nature of the relationship breakdown. We acknowledge that there are very specific situations - such as the end of an abusive relationship [9] that will have a profound effect on the central actors. To our knowledge we do not cover those situations here.

\section{Approach}

Individual, semi-structured, ethnographic interviews were used to generate a phenomenological understanding of the experiences of the participants, and the meanings they attached to those experiences. The researcher was respectful of the sensitivity of the topic throughout, utilizing skills from previous counseling training. Questions took two forms: open questions (e.g. How did you use social media during that time?) and probing/reflective questions (e.g. What, in particular, made you feel like that?). The researcher remained vigilant, looking for signs of distress in each participant, and using short breaks appropriately to enable participants to compose themselves when needed. Interviews took place over the course of 4 months, with each interview lasting between 90 and 150 minutes. Participants were recompensed with a $£ 10$ gift voucher. We stopped recruiting participants once we had reached information saturation. The University granted ethical approval for the study.

\begin{tabular}{|c|c|c|c|}
\hline Participant & $\begin{array}{c}\text { Gender } \\
\text { and Age }\end{array}$ & $\begin{array}{c}\text { Time since } \\
\text { separation }\end{array}$ & $\begin{array}{c}\text { Years } \\
\text { together }\end{array}$ \\
\hline A & M (29) & 2 yrs & $6 \mathrm{yrs}$ \\
\hline B & F (35) & 4 mths & $10 \mathrm{yrs}$ \\
\hline C & F (37) & 5 yrs & $8 \mathrm{yrs}$ \\
\hline D & F (27) & $8 \mathrm{mths}$ & $4 \mathrm{yrs}$ \\
\hline E & M (41) & $18 \mathrm{mths}$ & $11 \mathrm{yrs}$ \\
\hline F & M (67) & $7 \mathrm{yrs}$ & $34 \mathrm{yrs}$ \\
\hline G & F (68) & $7 \mathrm{yrs}$ & $34 \mathrm{yrs}$ \\
\hline H & F (27) & $2 \mathrm{yrs}$ & $4 \mathrm{yrs}$ \\
\hline
\end{tabular}

Table 1. Participant demographics

During the interviews, a variety of audio recordings and researcher notes were gathered. Data was analyzed using thematic analysis [2]. This method allows specific experiences and anecdotes to be grouped together by similar attributes, and then evolve into overarching themes 
through a process of analysis by the researcher. It is particularly useful for drawing insights from rich datasets provided by the interviews. With each pass through the interview data, the draft themes were refined until a set of distinct finalized themes emerged.

\section{FINDINGS}

Four overarching themes were identified: communicating about the separation, change in social status, dividing up the assets (digital and physical), and moving on and looking towards the future.

\section{Communicating about the separation}

\section{Spreading the news}

Technology acted as a broadcast service for news of the relationship breakdown, allowing quick dissemination and detaching participants from face-to-face emotional conversation. It was used both for wide broadcast to everyone in the user's contacts list (which could be their phone address book, email address book or friends on a social networking site) and to send a personal message to a select few:

"I couldn't face the thought of having to tell people and I just wanted them to know quickly. So I thought it would be easiest to text everyone in my phonebook and tell them. It was like ripping off a plaster - I thought there was no point hanging around." - Participant $A$

"I sent a text to my close friends saying 'Don't call me, I am fine, but we have split and I need some time to deal, I will be in touch soon'. I found that really helpful." - Participant C

As illustrated by these participants' comments, the innately asynchronous nature of text messages, emails and social media posts was valued in communicating news of a breakup to members of participants' social networks, either in selected groups or to everyone that they knew. Such 'break-up notification' messages did not require immediate responses from recipients of the information, and also importantly - did not require the message sender to engage in discussion of the breakup unless they chose to.

The medium through which a break-up notification message was sent had a knock-on effect, shaping who could see the responses sent to the original notification. Sending a text message resulted in text message responses, sent directly to the sender: while a message may be sent to a group of people, their replies are (by default) only received by the original message sender. However, if news of the breakup was sent via a social networking site, then very public responses could be given (if people responded), which exacerbated rather than reduced the emotions related to telling people:

"I thought if I put something matter of fact up on Facebook, then folk would know why I haven't been in touch, and then they would know when I saw them next. I was actually a bit embarrassed about the separation, but it is a small community and he is with someone else, so I needed people to know I knew. None of those awkward situations where people felt they needed to avoid me because they know some deep, dark secret. I was slightly staggered by the support. But the more responses there were, the more popular the update was. So it meant it kept being shown high up on Facebook, so I got to relive it over and over. Fab, eh!" - Participant D

As well as keeping the message visible for longer (if the social networking metrics deemed it to be most popular), the message defaulted to a persistent state [10], remaining available permanently through the individual's profile page (unless they chose to delete it at a later date). Participants highlighted that they had not considered the persistence of postings to social media at the time, only later when they became uncomfortable with the contents of their posts and associated responses. Further, some participants $(n=2)$ expressed surprise at the impact of amending their relationship status in their profile, not realizing that it would be posted as an update. Participant B blamed herself for not being 'tech smart':

"My worst move was changing my Facebook relationship status. It was like putting up an advert for everyone to ask what was happening, and how I was. I never felt so harassed, and they were mostly my friends!'-Participant $B$

In contrast, other participants $(n=4)$ were clear on the effects of changing their relationship status online, and saw this activity as part of the experience of working towards the 'new normal' [9] of their single state:

"I wouldn't want to be one of those people who changed status to 'It's complicated'. Nothing spurs intrigue more than a vague statement like that. A colleague did that last year, and I really found the whole thing annoying. But I did have to change my relationship status to move forward" Participant $C$

\section{Misunderstandings}

Optimism over the role of $\mathrm{CMCs}$ in facilitating communication between the partners in the relationship breakdown proved unfounded. The absence of visual and audio social cues associated with text-based CMCs resulted in misunderstandings:

"When we separated, we thought using email would be the best way to sort things out and communicate generally. We didn't want the kids to hear shouting on the phone. Trouble is, when you are emotional it is easier to misunderstand the tone of an email and for it all to spiral. We actually made things much harder for ourselves". - Participant $F$

Participants F and G (previously in a relationship together) had both expected asynchronous communication to be particularly useful in facilitating communication as it did not require both of them to be in the right frame of mind at the same time. However, they found that the tensions and 
emotions which were already associated with their breakup, coupled with the lack of social cues, meant they looked for a negative tone that was not necessarily present when the email was composed. This contrasts with findings from a previous study where the asynchronous nature of text-based exchanges mitigated some of the problems associated with verbal interaction [28] in this context. The variation in these findings could simply be attributed to differences in individuals' communication styles.

\section{Catharsis, Persistence and Regret}

New forms of mediated one-to-many communications such as Twitter and other social networking sites made it very easy to react first and think later, particularly because these technologies facilitated a culture of sharing one's thoughts without editing them first:

"I used Twitter to vent about stupid things that annoyed me during the day, like the man having an offensive telephone conversation on the train in the morning. When we split I would vent about my ex on there too. It felt right at first, and then I felt a bit exposed because it is so public." Participant E

Failure to consider the very public nature of messages posted on social networking sites was a cause of subsequent regret. The misconception that communications were ephemeral unless physically written on paper, only living on in the memories of the individuals who were communicating at the time, was also a source of regret as participants' awareness of the persistent nature of CMCs [5] grew:

"I was foolish really by thinking what I write was floating out into the ether, but somehow disappearing amongst all the other messages, never to be seen again. I guess I thought that people could see it for a few hours and then it was lost. Sadly, they are a little more fixed in concrete than that." - Participant D

Revenge and retribution were sought against ex-partners via social networking sites. Participants hoped that the public nature of the medium might hurt their ex-partner, or shame them into changing their behavior. While posting such content initially provided catharsis, there was subsequent regret at the persistence of this content amongst a very public audience:

"I shamed my ex on Facebook when he was behaving badly towards us. But when I say it out loud to you, I realized that it doesn't sound very grown up. Maybe that was a mistake" - Participant $H$

In contrast to this public venting behavior, the possibility of 'airing their dirty laundry in public' was repugnant to some of our participants $(n=2)$. These users worked hard to pause and consider the information that they posted online at a time when their emotions ran high, often having to completely disregard their visceral reaction:
"I watched everything I posted online and in text and emails. I knew that whatever was 'written' down could come back to bite me on the bum one day. I didn't want an ill thought-through tweet being read out in court, if it ever came to that." - Participant A

Impression management [14] was identified as an important focus for some participants, who felt under pressure to present themselves 'appropriately' throughout the process of the split and afterwards. They felt pressure both on how they physically presented themselves, and also how they presented themselves online. They felt that the relationship breakdown had made them vulnerable, and that even their closest peers would be watching - or even judging their responses:

"Every post I made after we split up was labored over. I wanted to make sure I wasn't being too happy, sad, bitter or grumpy. I felt under the spotlight, and thought if I posted that I had a really good night out, that people might think I was trying too hard or concerned that I wasn't home crying into my cake. In the end it was easier to keep a low profile." - Participant C

\section{A change in social status}

The pervasive aspects of technology - and indeed of photos, videos and text-based communications more widely - meant that links still existed to hold individuals together in spite of a relationship breakdown:

"I understand that we will never truly be disconnected. There will always be photos from parties or weddings in friends' albums that will show a connection. And I actually don't mind that. We are no longer together, but I can't honestly say that those years didn't happen or weren't worthwhile." - Participant C

Terms of service of Internet Service Providers (ISPs) have a direct influence on whether users have agency (control) over links that indicate that the relationship still exists: some of those links are semi-permanent, some are under control of the individual participants. Where active removal or deletion of the links was possible, it was seen as an act of closure, a way to let go of the past and a way to work towards a new normal [19]:

"It was hard, but one night after a month or so of splitting, I sat down and removed him from my relationship link, removed his sister who was down as my sister and untagged him from some of my group pictures. The pictures of just us together got deleted as well. I needed to do that to move on because as far as the Internet was concerned we were still very much connected and in a relationship. "- Participant $C$

Participant C's comments here also highlight a dilemma experienced by those who had been part of a long-term relationship: where to 'draw the line' between their past social identity as part of a couple, and their new, postseparation self. These findings reiterate those of Sas and Whitaker [32], highlighting that a relationship breakdown 
changes not only the relationship of the couple, but also their relationships with their wider social networks, both online and offline. Concrete examples of dilemmas reported by participants include:

- Who to remain friends with on social media? Should they remove joint friends who had initially been friends with their ex-partner first? "Culling your friends list on Facebook is always political, but when it comes after a breakup, it almost feels like you are each picking for your football team at school. And you will always have people upset that they haven't been picked by you." Participant E

- How to address the binary nature of friendship evident in the online context - friends/ not friends - when intending to maintain a close friendship with an expartner's sister, whilst not wanting to be too overt about the continuing friendship at first for fear of creating additional tensions with the ex-partner?

Technology also stopped people from letting go, and even facilitated holding on to the fraying edges of the relationship, using social networking sites to show their ex "what they were missing" or that "I am so over you - look what I am up to now".

"Don't laugh but I was obsessed with showing him I had moved on which - if I am honest - I hadn't, otherwise I wouldn't be thinking about him all the time. I had never posted to Facebook or Instagram as much as then, as I was determined to make my life look all the better for being single. I went out loads, and made sure I (or my friends) took loads of pictures having fun and going to different places. It was exhausting but it was what I needed to do" Participant $B$

Hanging on could evolve into "non-scary stalking" $(\mathrm{n}=2)$, with participants reporting that they monitored feeds on social networking sites about their ex-partner:

"I did do a bit of stalking - but non-scary stalking - I wasn't sat outside the house watching through a window or anything! I just checked what they were up to on Facebook and Twitter, to see what they were getting up to and who they were spending time with. I don't know why I was doing that, but I guess it was difficult going from being in someone's life to nothing." - Participant H

\section{Shared digital assets}

Dissolution of a co-habiting relationship brings with it the need to divide up shared assets. Participants reported that the division of shared physical (technology-based) assets had been a source of tension and negotiation.

While individuals had their own mobile phone, many of the participants had shared a laptop or desktop computer as a communal home computer, shared MP3 players for music in the home, and even shared hard drives for home media servers. Their use prior to relationship breakdown matched the 'Appliance Model' [5], whereby those residing together share use of available technology, having first deployed social protocols to mediate the sharing (for instance, sharing account and password details). This contrasts with a 'profile model' that orients towards each individual having his or her own profile and user accounts [5]. Shared ownership - while practical during the relationship - proved to be very difficult at and beyond the end of the relationship.

\section{The value of assets}

Determining how to share and divide physical digital assets was complicated, largely because of the value embedded within them. Financial value is significant during relationship breakdown, with adverse outcomes on financial wellbeing the norm - particularly for women [35]. However, beyond tensions centering on financial value of assets, the personal data that both parties stored on (or accessed from) devices - e.g. text, photos, music - could be the subjects of dispute. Beyond any possible financial value, this personal data could be imbued with emotional, intellectual or practical/ informational value [22].

The shared laptop/desktop was likely to contain data imbued with practical and informational value. The device often contained documents or accounts relating to the home. If the party leaving the shared home took the computer, the remaining party could struggle to access online billing and account numbers. In addition, loss of access to the computer resulted for some participants in a loss of access to online forms of communication that they found useful for social support - such as Skype and social networking sites. The isolating effect of loss of internet access during a relationship breakdown has previously been described by Dimond et al, in the context of abusive relationships [9].

The emotional value of shared physical (technologicalbased) assets also surfaced in interviews. This value was not necessarily linked to an asset's function, and could change in light of the relationship breakdown and the threat of loss. For Participant B, an object's emotional value was generated by its provenance and context, unrelated to its digital capability:

"I wanted the digital photo frame as it was a wedding gift from my aunt, who has since died. My ex found this ridiculous, because I didn't even know how to put photos on it. He was the one who played with it." - Participant B

Beyond the types of value identified above, participants were sensitive to an additional quality associated with digital assets: the potential to discomfit. Intimate relationships can generate intimate materials and memory cues [17]. At the end of a relationship, these intimate materials have the potential to make their author or subject feel uncomfortable, embarrassed or humiliated. A desire to delete these materials is common [32], rather than to willingly share such materials with an ex-partner: 
"My other half wanted copies of all our photos, but I wanted to be selective and removed the ones I felt a bit more sensitive about, you know the beach photos etc. After being together 10 years, there was lots to go through. So I kept just saying I couldn't burn them to a CD at the moment as it was broken, to buy me the time to sort them out." Participant B

\section{Dividing digital assets}

The challenge of dividing physical assets during a relationship breakdown is not new. Dividing up digital content is. This content could be based on a local physical device or in the cloud. Some of the data was very easy to deal with. For example, personal photographs were copied and shared with the ex-partner, with little concern over copyright or licensing agreements. While the curatorial process of choosing which photographs to share poses its own problems, the inherent ability to create multiple copies of digital artifacts painlessly resolves tensions over who gets which precious keepsake photo.

"We both got all the photos of the kids growing up. I am glad we had digital photos, which made it really easy because I would be upset not to have them all." Participant $H$

Difficulties occurred when content was collated, merged and embedded within other systems such as online repositories. As Moncur points out, "just because a user has data does not mean that they own it - even if they have paid for it" [22]. Music collections that were stored online and streamed, rather than owned as CDs and records, may have been stored in a joint/family account (a shared ownership account) to make it easier to produce playlists and to make listening to music a collaborative activity. Or a couple may have shared a password to a single-user account, enacting the aforementioned Appliance Model [5]. Ownership of a license to use content from a service provider, rather than owning it outright, posed distinct challenges for the separating couple:

- How do you divide up music albums between two people when they are 'stored' under a single online account in a repository such as iTunes?

- What are the legal implications to 'changing ownership' of music or films downloaded from the Internet?

- How do you remember what you had under a shared account, when you can no longer access the inventory? "I lost my music collection because we always used his iTunes account. I know I can replace them, and it is not even the principle of paying twice that frustrates me. It is that I can't remember everything I had off the top of my head, so what I have at the moment feels pretty rubbish." - Participant D

\section{Moving on}

Managing Practicalities

Every relationship divides responsibilities differently, however one identified problem amongst participants was where one party was responsible for sorting out the household bills and accounts. With service suppliers moving account management online, it became very difficult when the party who left the shared accommodation was the one who ordinarily managed the provision of utilities to the home. Problems occurred in trying to transfer accounts (largely managed online) to a new owner, as the systems rarely provide that option:

"We had a very amicable and methodical split. We sat down and made a list of everything which needed to be sorted out before one of us moved out. My ex-husband dealt with all the online billing for the telephone, gas, electric etc. So we sat down to sort it out, and there was no way to do this online. Not even in the help files. Eventually we found the appropriate number, but then had to navigate the 'press 1 for' list, and nothing seemed to fit. After about 30 minutes of trying different options, listening to irritating music and being put on hold, we got through to someone who could help. By that time we were a bit frustrated, and had only managed one (supplier) on the list. So we left the next one until the next day." - Participant $C$

Not all participants had the option for a mediated transfer of utilities bills. One participant's partner left the home and was not contactable again, and one refused to help. Neither of these participants knew where their accounts were held, and there was no documentation or paper trail in the house to follow, largely because of paperless billing:

"I tried to change the electricity supplier once I had found out which one it was. Don't even get me started on how difficult it is to find out who the supplier is. I was told it should be easy enough, but it was like I wanted access to codes to launch a nuclear missile. I had to keep explaining why I didn't have that information. Anyway, when I phoned the electricity company, they told me it would be easier to change account details if my other half had died than walked out on me!"' - Participant B

\section{Supporting distributed parents}

We found that technology could have a positive role in facilitating communication between distributed families. Having a shared online calendar space that acted as an intermediary was very popular with participants who had children, in much the same way as public awareness calendars are [26], as it helped to provide talking points and facilitated a connection for separated parents:

"We have a Google calendar for my daughter which is shared between us (and the grandparents too). We used it to hold all her appointments and clubs, and note down when she is staying with her dad. It also means my exhusband can phone at the right time, after dance class, and 
ask her about it in a way that tells her he knows what is going on, and cares about it. It is important to me that they have a good relationship, and I know the calendar really helps him. So I can help by keeping it up-to-date." Participant $B$

This finding echoes that of Odom et al. in their work investigating how interactive systems can support dynamic family structures. They too report that shared calendars facilitated connections between parents, even in situations where those parents were not on speaking terms. As both parties could see how the other contributed to managing their child's time, it provided positive tangible evidence of their investment in the co-parenting relationship [28].

Tools that facilitated more interactive communication were also popular, particularly when children were young and struggled with audio-only communication provided by the telephone. Often communication was set for pre-established windows of time:

"I love Skype. I was always going to speak to the kids every night, but with Skype I can see them and they can see me. It makes the situation easier to live with, and I hope it is good for them." - Participant A

One parent reported using Google Latitude, a (nowdiscontinued) service that allowed users to be tracked by specific people via their mobile phone on a Google map. This allowed the parent and child to feel a connection without communicating, because they could visualize where the other one was.

"We use Latitude, do you know it? It is like our own Marauder's Map from Harry Potter. I can check in on her and she can check in on me. We feel connected, but without having to come up with an excuse for a text message. Plus I can check she is home from her drama club before I call. We are quite sad that they don't do Latitude anymore." Participant E

\section{Summary of findings}

Our participants recalled strong, mainly negative, emotions in the context of their computer-mediated communications during their relationship breakdowns. Emotions expressed through online fora included distress, anger, vengefulness, obsession through online stalking and highly crafted (disingenuous) representations of a very social self. Reflecting on their use of technology during this period, participants expressed regret at what they posted, vulnerability at how they could appear through the lens of social media, embarrassment, a sense of necessary pain in communicating news of the breakup, and a feeling of being harassed online by well-meaning social network members. One participant's expression of a positive emotion, gratitude for the unexpectedly high level of support expressed online by friends, was tempered by regret as this also meant that her breakup notification post achieved high visibility and persistence on social media as a popular post.
At a time when they were already facing real difficulties in the analog world through relationship breakdown, participants struggled with additional difficulties generated by digital services that were designed for beginnings, not endings. Our participants encountered a range of obstacles to uncoupling themselves online. The simplistic binary approach to friendship offered by SNS - friend/ not friend created difficulties that would seem ridiculous offline, forcing individuals to 'unfriend' people that mattered to them because of the way that friendships are manifested publicly online. The division of digital assets also brought problems unique to the digital world, where 'ownership' is an increasingly problematic concept [27] and established domestic practice takes precedence over copyright and licensing agreements - at least until a relationship breaks down. Service suppliers' (e.g. provision of gas and electricity) online systems often failed to take relationship breakdown into account, creating unwelcome headaches for those affected.

On a positive note, one of the issues identified by Participant B - having her changed relationship status highlighted by Facebook on her Timeline - is now moot. Facebook has revised how it handles changes in relationship statuses; couples taking a positive and progressive step in their relationship, for example moving from 'In a relationship' to 'Engaged' are offered the opportunity to post this as a public 'Life Event' by default. In contrast, couples that terminate a relationship, for example, moving from 'Engaged' to 'Single' or 'Separated' are notified that this event will not appear on their News Feed by default.

\section{OPPORTUNITIES FOR DESIGN}

We invite the designers of online services to take common adverse life events into account just as much as they do positive ones. Online services are now (generally) very good at supporting online instantiations of new relationships - whether platonic, romantic, professional, or service-related. They are also good at maintaining the status quo - for example, Facebook reminders to wish existing friends 'Happy Birthday', LinkedIn's alerts when contacts have a work anniversary, routine provision of online bills for utilities. Online services are not so good at endings. Poor design in the face of an extremely common transitional life event, relationship breakdown, caused our participants to experience a range of negative emotions, and forced them to navigate additional hurdles in the process of separating. This seems unnecessary.

Herein, we highlight some design opportunities emerging out of this study - reducing misunderstandings, improving social media, supporting intimacy in distributed families, and revising service provision - that take relationship breakdown into account. 


\section{Reducing misunderstandings}

CMCs such as emails and social media have a way to go before they replicate the subtleties of offline communications. As Derks and Fischer note, "The lack of non-verbal signals in CMC would imply that emotional states can be overestimated or underestimated... In the case of conflicts this may more easily lead to an escalation of the conflict" [8:11]. Use of email to communicate with their expartner after breaking up certainly exacerbated tensions for some of our participants. We see opportunities here to examine how misunderstandings in text-based CMCs can be reduced through a range of non-verbal (visual) cues. In other contexts, emoticons can be useful in reinforcing messages and expressing emotions [7], but previous studies on their use have been undertaken in contexts that are not as emotionally charged as relationship breakups. It is questionable whether they could help to communicate emotional state in a sufficiently nuanced and mature manner in the context of relationship breakup.

\section{Enhancing social media}

\section{'Netiquette'}

Our participants valued the asynchronous nature of social media, email and text messages in sharing news asynchronously, finding it a useful way of avoiding giving difficult news in person. This has previously been observed in the context of bereaved individuals sharing news of a death with their social network [23]. The nature of the channel used for the breakup notification - public (a Facebook post) or targeted (a text message) - affected the response given. Participants did not welcome emotional responses that were aimed at a public audience.

Sensitively highlighting that a piece of news requires a personal response from recipients, not a public broadcast, could be a useful prompt for those who do not grasp tacit online social norms. Such prompting could also be useful for dissuading disgruntled ex-partners from making pronouncements online that they later regret. Of course, any such prompting would need to be designed very carefully to avoid becoming a new version of the irritating "Mr.Clippy" coach, once prevalent on Microsoft screens.

\section{Popular social media posts}

When a number of friends responded publicly (rather than via a private message) to a breakup notification on Facebook, it could lead to the notification becoming a 'top story' - thus gaining far more attention than its originator may have intended. It is likely that these notifications would also appear in subsequent 'On this day' messages ${ }^{1}$ and 'Look Back' videos issued by Facebook to support reminiscence - although the interviews were conducted before these features were introduced, and so our participants did not comment on these features. Automated

\footnotetext{
${ }^{1}$ https://www.facebook.com/help/439014052921484/
}

ranking of popular posts, and reuse in nostalgic reposts, could be improved to identify context and to avoid resurfacing emotionally painful memories in a manner which is beyond users' control and which may be very unwelcome [11]. More broadly, efforts to understand how to cue welcome memories [17] - and to avoid unwelcome ones - through mediated content would be valuable.

\section{Mediated support of intimacy in distributed families}

A significant part of being a member of a shared household is having available to you the resources to reason about one another's activities without any overt effort. Relationship breakdown means that, for people who are part of a family group rather than just (ex-) cohabiting partners, these ordinary resources are no longer going to be available for one of the people involved. An integral aspect to sustaining intimacy is the right to assume certain things about people, including certain kinds of knowledge: removing access to ordinary knowings is something that can significantly erode how intimacy is made manifest.

We see here an opportunity to support the ongoing intimacy that family life calls for, whilst recognizing that this intimacy takes on a new shape as a new normal is established in the relationships between the central actors. Even being aware of a parent's or a child's presence, without necessarily starting a conversation, is valuable in sustaining intimacy for distributed families. Looking at systems to promote a sense of connectedness and presence in a non-verbalized way between a child and a parent who no longer share a home every day presents an interesting next step. It is also one in which there is already significant engagement - albeit at the other end of life - in monitoring the activities of elderly relatives in more or less intrusive ways.

\section{Refining service provision}

\section{Disentangling}

The transfer of billing accounts, from the ex-partner who was moving out to the one who was remaining in the home, or from joint to single ownership, was surprisingly difficult. Participant B was told that it would have been easier if her partner had died. Indeed, the Tell Us Once service ${ }^{2}$ provides a good example here of sensitive service provision in the context of bereavement, which is worth emulating for those experiencing relationship breakdown. This service, provided by the UK Government, allows next of kin to report a death once, thus triggering a process that automatically amends an individual's status to 'deceased' across government services. This streamlines a once laborious and potentially distressing process for the bereaved. Facebook provides an option to memorialize or delete an account in the event of a user's death [23]. Perhaps an extension to these services is needed? - a central

\footnotetext{
${ }^{2}$ http://bit.ly/11177Pf
} 
digital breakup service, whereby all digital services can be adjusted to facilitate a 'breakup' of billing accounts, so that a couple's online status can be disentangled, thus matching the offline one.

\section{Cloning accounts}

Distinct to issues around who is named on billing accounts, participants were frustrated by the inability to remember what digital assets they had previously had access to via online repositories such as iTunes, when they shared an account with their partner. Remembering goes beyond a mere list. Using Netflix (a popular provider of on-demand Internet streaming media) as an example, a shared account encompasses not only a list of films, TV series and other media both viewed and to be viewed, but also user preferences and tailored recommendations. A straightforward service design opportunity presents itself here, in creating a facility to clone the online account - also presenting commercial benefit to service providers in the form of new customers. The concept of cloning accounts generalises to other situations where living circumstances change - for example, to young adults leaving the family home and beginning to live independently, who still want to watch the same kinds of media.

\section{FUTURE WORK}

This study focused on eight adults aged from 29 to 68 . Whilst the sample size was modest, reflecting the difficulty in recruiting participants for a study in this very sensitive context, participants' experiences and relationship durations were varied. In future work, we will consider the role of technology in relationship breakdown amongst younger adults and teenagers, in comparison to the experiences of somewhat older people reported on in this paper. We anticipate that there will be less decoupling of assets, yet there will still be a need to manage identity after break-up (perhaps even more so as digital engagement is commonly deeper and more extensive amongst young adults than older ones). We will also study the effects of relationship duration and socioeconomic status. How much identity management is done to erase the past, depending on the duration of the relationship? How does a division of (digital) assets take place when there are scarce resources? participants in our study were comparatively affluent.

Our participants lived within the UK. The data presented here does need to be understood within the context it was gathered. Each breakdown is unique, and no attempts are made to determine whether the results will generalize to other populations. Opportunities exist to test the generalisability of our overall themes to alternative relationship breakdown settings and sociocultural contexts.

\section{CONCLUSIONS}

This study has contributed to the small but growing body of research into the role of digital technologies during relationship breakdown. It has examined where technology helps and complicates the breakdown, and highlighted opportunities for design. Our findings share common ground with work on other common yet disruptive transitions across the human lifespan- e.g. [21,24,36]. As we develop a deeper understanding of the role of technology during these transitions, there are rich opportunities to draw insights together and to design technologies that can support individuals during the more challenging periods in their lives.

\section{ACKNOWLEDGMENTS}

This research was supported by Research Councils UK (project reference EP/L00383X/1) and an EPSRC DTA studentship. We are grateful to our participants for their participation in this study.

\section{REFERENCES}

1. Paul R. Amato. 2000. The Consequences of Divorce for Adults and Children. Journal of Marriage and Family 62, 4: 1269-1287. http://doi.org/10.1111/j.17413737.2000.01269.x

2. Virginia Braun and Victoria Clarke. 2006. Using thematic analysis in psychology. Qualitative Research in Psychology 3, 2: 77-101. http://doi.org/10.1191/1478088706qp063oa

3. Jed R. Brubaker, Gillian R. Hayes, and Paul Dourish. 2013. Beyond the Grave: Facebook as a Site for the Expansion of Death and Mourning. The Information Society 29, 3: 152-163.

http://doi.org/10.1080/01972243.2013.777300

4. Jed R Brubaker, Funda Kivran-Swaine, Lee Taber, and Gillian R Hayes. 2012. Grief-Stricken in a Crowd: The Language of Bereavement and Distress in Social Media. ICWSM.

5. AJB Brush and Kori Inkpen. 2007. Yours, Mine and Ours? Sharing and Use of Technology in Domestic Environments. In UbiComp 2007: Ubiquitous Computing. 109-126.

6. L. Crystal Jiang and Jeffrey T. Hancock. 2013. Absence Makes the Communication Grow Fonder: Geographic Separation, Interpersonal Media, and Intimacy in Dating Relationships. Journal of Communication 63, 3: 556-577. http://doi.org/10.1111/jcom.12029

7. Daantje Derks, Arjan E. R. Bos, and Jasper von Grumbkow. 2008. Emoticons in Computer-Mediated Communication: Social Motives and Social Context. CyberPsychology \& Behavior 11, 1: 99-101. http://doi.org/10.1089/cpb.2007.9926

8. Daantje Derks, Agneta H. Fischer, and Arjan E. R. Bos. 2008. The role of emotion in computer-mediated communication: A review. Computers in Human Behavior 24, 3: 766-785. http://doi.org/10.1016/j.chb.2007.04.004 
9. Jill P. Dimond, Casey Fiesler, and Amy S. Bruckman. 2011. Domestic violence and information communication technologies. Interacting with Computers 23, 5: 413-421. http://doi.org/10.1016/j.intcom.2011.04.006

10. J Donath. 2004. Sociable media. In (1st ed.), William S Bainbridge (ed.). Berkshire Publishing Group, Massachussetts, USA.

11. Josh Dzieza. 2015. Facebook's new nostalgia feature is already bringing up painful memories. The Verge. Retrieved July 22, 2015 from http://www.theverge.com/2015/4/2/8315897/facebook-onthis-day-nostalgia-app-bringing-back-painful-memories

12. Judith A. Feeney and Patricia Noller. 1992. Attachment style and romantic love: Relationship dissolution. Australian Journal of Psychology 44, 2: 69-74. http://doi.org/10.1080/00049539208260145

13. Lorna Gibson and Vicki L. Hanson. 2013. Digital Motherhood: How Does Technology Help New Mothers? Proceedings of the SIGCHI Conference on Human Factors in Computing Systems, ACM, 313-322.

http://doi.org/10.1145/2470654.2470700

14. Erving Goffman. 1959. The presentation of self in everyday life. Double Day, Garden City, NY, USA.

15. Oliver L. Haimson, Jed R. Brubaker, Lynn Dombrowski, and Gillian R. Hayes. 2015. Disclosure, Stress, and Support During Gender Transition on Facebook. Proceedings of the 18th ACM Conference on Computer Supported Cooperative Work \& Social Computing, ACM, 1176-1190. http://doi.org/10.1145/2675133.2675152

16. Julie H. Hall and Frank D. Fincham. 2006. Relationship Dissolution Following Infidelity: The Roles of Attributions and Forgiveness. Journal of Social and Clinical Psychology 25, 5: 508-522.

http://doi.org/10.1521/jscp.2006.25.5.508

17. Elise van den Hoven and Berry Eggen. 2014. The Cue Is Key: Design for Real-Life Remembering. Zeitschrift für Psychologie 222, 2: 110-117. http://doi.org/10.1027/21512604/a000172

18. Michael Massimi. 2013. Exploring Remembrance and Social Support Behavior in an Online Bereavement Support Group. Proceedings of the 2013 Conference on Computer Supported Cooperative Work, ACM, 1169-1180. http://doi.org/10.1145/2441776.2441908

19. Michael Massimi, Jill P. Dimond, and Christopher A. Le Dantec. 2012. Finding a New Normal: The Role of Technology in Life Disruptions. Proceedings of the ACM 2012 Conference on Computer Supported Cooperative Work, ACM, 719-728.

http://doi.org/10.1145/2145204.2145314

20. Michael Massimi, Richard Harper, and Abigail J. Sellen. 2014. "Real, but Glossy": Technology and the
Practical Pursuit of Magic in Modern Weddings. Proc. CSCW'14, ACM, 854-865. http://doi.org/10.1145/2531602.2531682

21. Michael Massimi, Svetlana Yarosh, Madeline E. Smith, and Joseph Jofish Kaye. 2014. Designing Technology for Major Life Events. CHI'14 Extended Abstracts on Human Factors in Computing Systems, ACM, 83-86. http://doi.org/10.1145/2559206.2559235

22. W Moncur. 2015. Digital ownership across lifespans. In Ageing and the Digital Life Course, C. Garratini and D Prendergast (eds.). Berghahn Books.

23. Wendy Moncur, Jan Bikker, Elaine Kasket, and John Troyer. 2012. From Death to Final Disposition: Roles of Technology in the Post-Mortem Interval. Proc. CHI'12, ACM, 531-540. http://doi.org/10.1145/2207676.2207750

24. Wendy Moncur, Judith Masthoff, Ehud Reiter, Yvonne Freer, and Hien Nguyen. 2014. Providing Adaptive Health Updates across the Personal Social Network.

Human-Computer Interaction 29, 3: 256-309. http://doi.org/10.1080/07370024.2013.819218

25. Moncur, W. and D. Kirk. 2014. An Emergent Framework for Digital Memorials. Proc. DIS'14, ACM Press, 965-974.

26. Carman Neustaedter, A. J. Bernheim Brush, and Saul Greenberg. 2009. The Calendar is Crucial: Coordination and Awareness Through the Family Calendar. ACM Trans. Comput.-Hum. Interact. 16, 1: 6:1-6:48.

http://doi.org/10.1145/1502800.1502806

27. William Odom, Abi Sellen, Richard Harper, and Eno Thereska. 2012. Lost in translation: understanding the possession of digital things in the cloud. Proc. CHI '12, ACM, 781. http://doi.org/10.1145/2207676.2207789

28. William Odom, John Zimmerman, and Jodi Forlizzi. 2010. Designing for Dynamic Family Structures: Divorced Families and Interactive Systems. Proceedings of the 8th ACM Conference on Designing Interactive Systems, ACM, 151-160. http://doi.org/10.1145/1858171.1858199

29. Office for National Statistics. 2014. What percentage of marriages end in divorce?. HM Government, UK. Retrieved May 19, 2015 from

http://www.ons.gov.uk/ons/rel/vsob1/divorces-in-englandand-wales/2011/sty-what-percentage-of-marriages-end-indivorce.html

30. Office for National Statistics. 2015. Civil Partnerships in the UK, 2013. HM Government, UK. Retrieved May 19, 2015 from http://www.ons.gov.uk/ons/rel/vsob2/civilpartnership-statistics--united-kingdom/2013/stb-civilpartnerships-2013.html

31. Galena K. Rhoades, Claire M. Kamp Dush, David C. Atkins, Scott M. Stanley, and Howard J. Markman. 2011. Breaking Up is Hard to do: The Impact of Unmarried 
Relationship Dissolution on Mental Health and Life Satisfaction. Journal of family psychology 25, 3: 366-374. http://doi.org/10.1037/a0023627

32. Corina Sas and Steve Whittaker. 2013. Design for forgetting: disposing of digital possessions after a breakup. Proceedings of the SIGCHI Conference on Human Factors in Computing Systems, ACM, 1823-1832. Retrieved January 6, 2015 from http://dl.acm.org/citation.cfm?id=2466241

33. Irina Shklovski, Robert Kraut, and Jonathon Cummings. 2008. Keeping in Touch by Technology: Maintaining Friendships After a Residential Move. Proceedings of the SIGCHI Conference on Human Factors in Computing Systems, ACM, 807-816. http://doi.org/10.1145/1357054.1357182

34. Ty Tashiro and Patricia Frazier. 2003. "I'll never be in a relationship like that again": Personal growth following romantic relationship breakups. Personal Relationships 10, 1: 113-128. http://doi.org/10.1111/1475-6811.00039

35. D de Vaus, M Gray, L Qu, and D Stanton. 2010. Relationship breakdown and social exclusion: A longitudinal analysis. Proc. 10th Australian Institute of Family Studies Conferences.
36. T Walter, R Hourizi, W Moncur, and S Pitsillides. 2012. Does the internet change how we die and mourn? An overview. Omega: Journal of Death \& Dying 64, 4: 275302.

37. Svetlana Yarosh and Gregory D. Abowd. 2011. Mediated Parent-child Contact in Work-separated Families. Proceedings of the SIGCHI Conference on Human Factors in Computing Systems, ACM, 1185-1194. http://doi.org/10.1145/1978942.1979120

38. Svetlana Yarosh, Yee Chieh "Denise" Chew, and Gregory D. Abowd. 2009. Supporting Parent-child Communication in Divorced Families. Int. J. Hum.Comput. Stud. 67, 2: 192-203. http://doi.org/10.1016/j.ijhcs.2008.09.005

39. Xuan Zhao and Siân E. Lindley. 2014. Curation Through Use: Understanding the Personal Value of Social Media. Proceedings of the SIGCHI Conference on Human Factors in Computing Systems, ACM, 2431-2440. http://doi.org/10.1145/2556288.2557291

40. 2009. Facebook fuelling divorce, research claims. The Telegraph. Retrieved from http://www.telegraph.co.uk/technology/facebook/6857918/ Facebook-fuelling-divorce-research-claims.html 